\title{
Ensinar Antropologia para não Antropólogos: experiências e fronteiras em enfermagem
}

\author{
Maria Manuel Quintela ${ }^{1}$ \\ ${ }^{1}$ Escola Superior de Enfermagem de Lisboa, Lisboa, PT
}

\section{Resumo}

Neste artigo, pretende-se refletir sobre o ensino de antropologia para não antropólogos. Essa reflexão é feita a partir da nossa experiência de docência em cursos de enfermagem, apresentando algumas respostas possíveis para os dilemas surgidos nesse percurso. A narrativa é feita em dois eixos, a experiência e as fronteiras. O primeiro, centrado nas opções tomadas relativas aos conteúdos programáticos, à metodologia e às estratégias de ensino-aprendizagem utilizadas na linha antropológica da orientação do "olhar" para a presença da diferença e da diversidade; o segundo, sobre os dilemas surgidos em sala de aula no contato com os estudantes, em que se jogam interfaces de saberes e se questionam as fronteiras disciplinares.

Palavras-chave: Ensino Antropologia. Estudantes Enfermagem. Fronteiras Disciplinares. Saúde. Portugal.

\section{Teaching Anthropology for Non-Anthropologists: experience and borders in nursing degree}

\begin{abstract}
This paper intends to reflect on teaching anthropology for non-anthropologists. This reflection is based on our teaching experience in nursing degree, presenting some possible answers to the dilemmas that arise along this path. The narrative is based on two axes, experience and borders. The first, centered on the choices, made regarding the syllabus, methodology and teaching-learning strategies used in the line of the anthropological 'view' towards the presence of difference and diversity; the second, about the dilemmas that arise in the classroom in contact with students, in which knowledge interfaces are played and disciplinary boundaries are questioned.
\end{abstract}

Keywords: Teatching Antropology. Students Nursing. Health. Disciplinary boundaries. Portugal. 


\section{Introdução}

$\mathrm{N}^{\mathrm{es}}$ este artigo, pretendo responder ao desafio que me foi feito pelos coordenadores deste número temático: o de escrever e refletir sobre a experiência do ensino de antropologia em cursos de graduação/licenciatura em enfermagem. Faço isso do lugar em que me encontro há mais de 25 anos - ensinar/formar em antropologia para não antropólogos. As questões/dilemas/reflexões particulares que esta experiência foi colocando ao longo do percurso profissional foram objeto de um primeiro debate/reflexão em 2006, no Colóquio da Associação Portuguesa de Antropologia (APA). A mesa intitulada “Antropólogos fora de água: o ensino da antropologia para não antropólogos" foi organizada por mim e pela Teresa Fradique como resultado das nossas conversas e da partilha das inquietações do nosso quotidiano no ensino fora da academia dos antropólogos. Ela, docente numa escola de artes, eu, numa escola de enfermagem (artes e saúde). Nesse encontro, os colegas que participaram no debate eram docentes em cursos de várias áreas disciplinares (de que são exemplos, entre outros: pedagogia, artes, saúde, serviço social). Uma primeira distinção surgia - os que, como nós, eram docentes em escolas do Ensino Superior Politécnico e aqueles que eram docentes em Universidades ${ }^{1}$. Os objetivos daqueles que formávamos não eram exatamente os mesmos. Os primeiros, mais vocacionados para uma vertente da prática profissional, e os outros, para a investigação. Então surge a primeira questão que se coloca no ensino da antropologia para não antropólogos: quem são os estudantes, futuros profissionais de quê?

Os estudantes para quem tenho lecionado antropologia, na graduação, são futuros profissionais de enfermagem. Não se espera, portanto, que sejam antropólogos e/ou cientistas sociais, mas sim que sejam profissionais que, em lato sensu, prestem cuidados de saúde a indivíduos, grupos e comunidades em todas as circunstâncias de vida, no processo saúde-doença e em todas as etapas cronológicas.

Organizei este texto, tanto a partir das questões que me foram colocadas pelos estudantes de licenciatura (graduação) no decurso das aulas como por aquelas que fui colocando a mim mesma ao longo do percurso como docente. Essas questões surgiram no modus vivendi/fazendi do imperativo de construir programas (ementas) de unidades curriculares (ciências sociais, sociologia e antropologia) para os diferentes níveis de formação ( $1^{\circ}$ e $2^{\circ}$ nível - licenciatura e mestrado).

A primeira formulação a fazer é: o que um estudante de enfermagem precisa conhecer do corpo teórico-metodológico dessa disciplina para a sua futura prática profissional?

Em Portugal, há dois sistemas de ensino superior: o ensino superior politécnico e o ensino universitário. 
De acordo com a especificidade do curso lecionado, são orientados os conteúdos de uma forma pragmática, mas na linha antropológica da orientação do olhar para a presença da diferença e da diversidade, que estimule os futuros profissionais de enfermagem a criar soluções criativas perante situações problema e não, apenas, reagir normativamente na resolução delas. Pretende-se também que a unidade curricular contribua para as práticas de cuidados de saúde mais humanistas, problematizando o óbvio e o natural. Para tal, discutem-se questões de natureza epistemológica sobre as classificações/taxonomias/formas de organização e leitura do mundo, enfatizando suas diversidades. Esse aspeto é particularmente importante na enfermagem e nos cursos de saúde, uma vez que são profissões em que há a preocupação da regulação de cada ato, por meio de protocolos, sendo, por vezes, apresentados como sendo as únicas formas possíveis de prestar cuidados de saúde. Nas práticas de enfermagem são disso expressão algumas nomenclaturas normativas de classificação de doentes e das intervenções de enfermagem (por exemplo: o designado "diagnóstico de enfermagem" de acordo com a Classificação Internacional para a Prática de Enfermagem (CIPE)).

Ao elaborarmos a ementa da unidade curricular e ao definirmos os objetivos de aprendizagem, é necessário ter em atenção que as ciências sociais e a antropologia em particular nesse contexto não são disciplinas centrais no curso, mas complementares. Porém, são essenciais para que os estudantes, futuros profissionais, possam compreender a arena e os atores sociais, cujo objeto da prática profissional se desenvolve - a realidade social. Partindo dessa premissa, logo se coloca uma primeira reflexão sobre noções de margem e de fronteira, relativamente à situação da disciplina de antropologia face à disciplina de enfermagem no currículo escolar. A margem, no sentido de um saber secundário com o qual não é estabelecido o diálogo; a fronteira como a afirmação da demarcação de dois campos disciplinares. Há então que construir pontes entre margens. Como toda a construção, esse é um processo lento, que mesmo sendo planeado e pensado, a realidade com que nos confrontamos em sala de aula nos surpreende continuamente. Assim, a experiência nos leva a aferir/a inventar por meio de tentativa e erro novas estratégias de ensino/aprendizagem num trabalho de equipe ${ }^{2}$.

Nesse sentido, organizei a narrativa em dois eixos: a experiência docente e as fronteiras disciplinares. Essa opção advém da reflexão que fiz quando da preparação da comunicação apresentada durante o I $8^{\text {th }}$ IUAES, WORLD (OF) ENCOUNTERS: the Past, Present and Future of Anthropological Knowledge, realizado em Florianóplis (Brasil), em julho de 2018, no Painel In the intersection between Anthropology and Education: weaving possibilities ${ }^{3}$, como sendo aquela que me permitiria melhor pensar sobre o ensino na e da saúde no contexto das ciências sociais e, particularmente, a partir da filiação disciplinar da antropologia. E, simultaneamente, me surgiu com um potencial analítico e de síntese de algumas questões que se colocam ao ensino de antropologia em cursos de saúde.

\footnotetext{
A equipe pedagógica foi constituída nos últimos 10 anos por: Lina Antunes (2009-2019); Telmo Calamote (2009); José Mapril (2010); Bruno Coelho (2011); Sofia Marinho (2012-2019); Luiz Vasconcelos (2013-2019); Margarida Moz (2014-2019) e Jorge Varanda (2017-2018) e Mónica Saavedra (2019).

3 Esta comunicação, intitulada "Teatching anthropology in nursing and health degrees: between experiences, margins and borders", foi apresentada neste painel Painel Aberto (101), coordenado por Alexander Cordoves; Ari José Sartori e Hélder Pires Amâncio na sessão 1, coordenada por Alexander Cordoves, Antonella Tassinari e Susana Matos Viegas.
} 
O primeiro, a experiência, se, por um lado, permite partilhar a experiência de ensino num curso de saúde - a enfermagem -, por outro, envolve falar num tipo de abordagem teórica e dos temas de investigação da antropologia sobre a saúde, como as experiências da doença, da dor, do sofrimento, do adoecer e dos tratamentos.

O segundo, as fronteiras, como o lugar disciplinar relacional das várias disciplinas: ciências sociais face às ciências da saúde, antropologia em relação às ciências sociais e da saúde; enfermagem face às outras ciências da saúde, particularmente à medicina.

O lugar em que me situo tem sido, também, o da margem e o da fronteira. Primeiramente, na formação inicial em enfermagem, estava na margem face às ciências sociais. Posteriormente, após a formação nessa área, foi necessário criar a distância analítica para pensar a fronteira, como antropóloga. É a partir daqui que falo sobre a experiência docente, maioritariamente no campo da antropologia; ou seja, de ensinar antropologia em cursos de enfermagem há quase três décadas. Falo na fronteira como um conceito antropológico no qual se produz a alteridade e se constroem identidades (COEHEN, 1999), mas também nas fronteiras disciplinares e epistemológicas, questionando se a fronteira se torna um lugar de demarcação e afirmação da diferença ou o lugar de trocas e de diálogo. Refiro-me aqui particularmente às ciências sociais e às ciências naturais/saúde, em grosso modo. Pois é entre estas que tem sido desenvolvida a minha atividade profissional e onde as questões, de natureza teórico-metodológica e pragmática, se têm colocado.

\section{A Experiência de Ensino: O que ensinar? A quem? E como ensinar?}

Ao ter que elaborar uma ementa curricular num curso para estudantes de enfermagem, não estudantes de antropologia ou ciências sociais, surgem de imediato algumas questões relativas às opções a tomar na seleção dos conteúdos programáticos: a quem se dirige o curso? Por quê e como fazê-lo? Qual o nível de exploração de uma temática, de um autor, de uma teoria? Como não se aprofundam conteúdos, sem, no entanto, os banalizar, sem ser reducionista? Quais são então aqueles conceitos tomados como fundamentais nesse contexto de formação (para a antropologia e para a enfermagem) ? ${ }^{4}$ Qual o objeto e a arena da sua prática profissional?

Tentaremos ao longo deste texto partilhar com o leitor as respostas que fomos encontrando para as nossas próprias questões. Sabendo nós que o curso é dirigido para a formação de futuros enfermeiros, a nível da licenciatura ( $1^{\circ}$ nível), é essencial conhecermos a filosofia da instituição, bem como os objetivos e as competências desejadas de um enfermeiro e, sobretudo, o que se espera do estudante no final do $1^{\circ}$ ano do curso.

$\mathrm{Na}$ apresentação do curso da ESEL no portal on-line, pode-se ler que os "estudantes que concluírem o Curso de Licenciatura em Enfermagem estão habilitados a prestar cuidados gerais de enfermagem ao indivíduo, família e comunidade". E que, no caso específico desse estabelecimento de ensino, o curso de Licenciatura em Enfermagem5,

\footnotetext{
4 No momento em que revejo este texto escrito em 2019, encontro-me de novo com algumas dessas questões no planeamento deste novo ano letivo (2020-2021) pós e durante pandemia da COVID-19 que me obriga a rever estratégias de ensino aprendizagem e metodologias de ensino face ao ensino misto - on-line e presencial, que não são objeto aqui de análise, mas que o serão com certeza em trabalhos futuros.

5 O curso de licenciatura em Enfermagem em Portugal é de quatro anos letivos, e o título de enfermeiro só assim pode ser obtido. Não existe, como no Brasil, o Técnico de Enfermagem.
} 
[...] confere uma formação científica, técnica, humana e cultural, da mais elevada qualidade, no âmbito da prestação, investigação e gestão de cuidados de enfermagem gerais à pessoa ao longo do seu ciclo de vida, à família, grupos e comunidade, atendendo aos diferentes níveis de prevenção.

Na medida em que se espera que atuem nos três níveis de prevenção, o campo da praxis será tanto as instituições de saúde, hospital e centros de saúde como as casas/ domicílios; ou seja, em qualquer lugar em que essas pessoas ou grupos se encontrem, se tomarmos como linha de referência a Conferência de Alma-Ata (1978) .

\subsection{Ensinar o Quê?}

A lógica que presidiu à elaboração do programa como organizadora dos conteúdos programáticos partiu da tentativa de resposta às questões anteriormente formuladas em quatro dimensões de análise ${ }^{7}$ : 1) A antropologia e a sociologia no conhecimento da realidade social; 2) Para a análise da relação saúde, sociedade e cultura; 3) Para a análise dos processos sociais e experiências de adoecer e tratamento; e 4) Questões contemporâneas e saúde: processos de transformação social.

Optei por abordar essas dimensões, por meio da seleção de conceitos-chave a partir dos quais se constrói a narrativa, desenvolvendo-a do mais geral para o particular. Assim, começamos por abordar no ponto I como o campo disciplinar se constrói e quais os seus autores fundadores, as perspetivas teóricas e os métodos. No ponto II analisamos os conceitos de cultura e sociedade (estrutura social, papéis sociais, normas e valores) para, posteriormente, fazermos a introdução ao campo da saúde e da doença. Estas como dimensões sociais, entre muitas outras, plenas de diversidade, que expressam diferentes visões do mundo de acordo com os contextos históricos, culturais e sociopolíticos. No ponto III desenvolvemos os temas relativos ao corpo, à doença, à dor, ao sofrimento, aos sistemas médicos e às práticas terapêuticas. Por fim, no ponto IV são discutidas e exploradas, por relação à saúde, as seguintes temáticas: religião e saúde; família e parentesco; rituais, gênero, migrantes e migrações; cidadania em saúde.

Nesse sentido, é necessário que primeiramente os estudantes conheçam o campo das ciências sociais, particularmente a antropologia e a sociologia (autores, conceitos e métodos). O objetivo é não a-historicizar os processos de formação disciplinar (e a saúde) e contextualizá-los nas suas dimensões sociais, históricas e políticas para que eles possam compreender também as fronteiras do seu próprio campo disciplinar, bem como para reconhecer o lugar onde as suas práticas profissionais se desenvolvem, como uma realidade social.

\footnotetext{
" Refiro-me à Conferência Internacional sobre Atenção Primária de Saúde, realizada em 1978 em Alma-Ata, no Cazaquistão.

A unidade curricular Antropologia e Sociologia, neste formato curricular, é lecionada desde o ano lectivo 2012-2013 no $1^{\circ}$ ano, no $1^{\circ}$ semestre do curso (6ECTS), com um total de horas de contato de 81 horas, distribuídas por aulas teóricas (T), 22 horas teórico-práticas (TP) e 10 horas de trabalho de campo (TC). Neste semestre, os estudantes têm um total de seis unidades curriculares (Psicologia, História e Epistemologia de Enfermagem; Anatomia; Microbiologia e Aprender ao Longo da Vida) e uma média de 30 horas de aulas semanais. A média de estudantes inscritos nesta unidade curricular por ano letivo variou entre os 330 e os 400 estudantes distribuídos por oito turmas nas aulas TP e TC e quatro turmas nas aulas $\mathrm{T}$.
} 
Há três conceitos, categorias, que são utilizados transversalmente em várias unidades curriculares ao longo da graduação (licenciatura) e a partir dos quais se pode construir a narrativa - sociedade, cultura e saúde. É necessário abordá-los com cuidado epistemológico, insistindo no rigor da análise conceptual que contrarie a tendência à reificação (naturalização) desses conceitos como categorias fixas, que com facilidade se usam e abusam, caindo na banalização de um jargão - como é exemplo e acontece frequentemente com uso da noção de cultura. Na mesma lógica, aprender também a problematizar os sistemas de classificação social, para pensar as nomenclaturas utilizadas nas práticas dos cuidados de saúde - como uma entre muitas - e não a única (por exemplo: o uso das designações cliente/doente/paciente/utente). Nessa perspetiva, problematizar como se pensa então a alteridade/a diferença, se esta é acentuada (exotizando-a) ou se a diversidade se potencializa como um campo de diálogo, de descoberta e de criatividade que possibilita práticas mais humanistas.

Uma das grandes dificuldades em selecionar temas, autores e textos para operacionalizar a unidade curricular tem sido o fato de ter de compactar num semestre uma unidade curricular que é designada como Antropologia e Sociologia; sobretudo na escolha dos autores que tendo que ser apresentados de uma forma breve, não o fazer de uma forma reducionista. Razão pela qual se opta por tentar conciliar autores de referência na própria história das disciplinas, com os conceitos que tomamos como conceitos-chave, necessários para a aprendizagem destas num curso de enfermagem. Por isso, tomamos como eixo orientador para abordar primeiramente dois dos conceitos-chave: a sociedade e a cultura. E nessa primeira abordagem dá-se a conhecer de que forma autores como Durkeim, Weber e Marx analisaram a relação indivíduo/sociedade.

Para posteriormente a abordagem ser orientada no sentido weberiano de uma sociologia compreensiva, por ser aquela que pragmaticamente nos parece mais adequada nesse contexto.

Na mesma linha se faz a abordagem ao conceito de cultura, começando pela relação entre a história da disciplina e o conceito de cultura, partindo de Eduard Tylor, Franz Boas, B. Malinowski, Margaret Mead até Clifford Geertz; este último como o orientador da abordagem das visões de mundo e de outras realidades. Entendemos que só depois de um conhecimento prévio desses autores e de alguns conceitos-chave se pode compreender a leitura de outros autores, particularmente daqueles da Antropologia da Saúde que versam o corpo, a saúde, a doença, o sofrimento, a dor e as práticas terapêuticas ${ }^{8}$.

Nesse sentido, a etnografia é importante como forma de orientar e de construir um olhar na compreensão da diversidade e da diferença, optando-se metodologicamente pela realização de um exercício de observação etnográfica, designado como Lisboa (as) a pé: olhar a diversidade e as interacções sociais, como uma estratégia de ensino/aprendizagem". Precedem a realização desse exercício aulas teóricas-práticas nas quais são analisados os textos, previamente lidos pelos estudantes (assim se supõe) - Malinowski (1997), Goffman (1985), Oliveira (1998) e Velho (1987) - e é construída uma grelha (roteiro)

\footnotetext{
8 Um dos textos que primeiramente é discutido na introdução ao tema da saúde e que consegue despertar o interesse dos estudantes é "Antropologia, Saúde e doença: uma introdução ao conceito de cultura aplicado às ciências da saúde" (LANGDON; WIIK, 2010).

9 Note-se que este exercício era efetuado no período anterior à pandemia COVID-19.
} 
de observação. Esse exercício de observação etnográfica é composto de dois momentos na "rua" ( o campo) e por dois momentos em sala de aula ${ }^{10}$. No primeiro ${ }^{11}$, os estudantes têm como objetivo mapear um território - um lugar da cidade de Lisboa (uma rua, uma praça, um mercado, uma estação de transportes ) - sorteado em sala de aula e fazer uma descrição da observação daquilo que constroem como o terreno de observação etnográfica, para o segundo momento ${ }^{12}$. Essa descrição é apresentada e discutida com o (a) docente e colegas na sala de aula. Os resultados desse exercício são apresentados em três sessões letivas, que correspondem a seis horas, devido ao elevado número de estudantes por turma. Cada turma tem oito grupos ${ }^{13}$. Esse é também o primeiro momento de avaliação (o trabalho de grupo).

Já no bloco III, com relação à análise dos processos de adoecer e tratamento, apelamos para a experiência dos estudantes relativamente a situações de mal-estar, doença e cuidados de saúde. Um dos exemplos prosaicos, mas que tem sido eficaz naquilo que queremos transmitir, tem sido utilizarmos a dor de cabeça para explorar explicações possíveis para a causa desse mal-estar. Aí fazemos o exercício de imaginação de justificações diversas de acordo com os atores sociais envolvidos, sobretudo aqueles relativos ao contexto familiar, recorrendo a alguns estereótipos. Ou seja, quem é o elemento da família que dá as razões explicativas para a "dor de cabeça" e como o faz (imaginando diálogos possíveis: no caso de ser a mãe ou o pai a fazê-lo - andaste nas noitadas, precisas é de dormir; se for o irmão/ã, o amigo/a - estás de ressaca (tomaste um porre); a vizinha - toma um chá de camomila; a avó - põe uma rodela de batata na cabeça). Assim, de acordo com as justificações apresentadas para a dor de cabeça compreenderem a diversidade dos tratamentos possíveis ( tomar uma aspirina, colocar na cabeça uma rodela de batata, dormir, tomar um café) e a opção de itinerários terapêuticos (ir ao centro de saúde, ir ao hospital, ir à curiosa tirar o mau-olhado ou simplesmente ficar em casa, dormir e ou tomar um chá).

Discutir estereótipos e preconceitos associados ao conhecimento do senso comum torna-se mais evidente no bloco/ponto IV - Para a análise dos processos de transformação social uma vez que os temas abordados (religião e saúde; família, parentesco e gênero; migrações e migrantes, cidadania) suscitam maior curiosidade e participação dos estudantes e se sentem detentores de conhecimento, como sujeitos sociais que conhecem e vivem na realidade social.

\footnotetext{
${ }_{10}$ Na rua têm atribuído dois períodos de seis horas cada. Em sala de aula três sessões letivas (6 horas)

${ }^{11}$ No primeiro momento, os estudantes terão como objetivo conhecer e mapear o território de observação, utilizando a grelha de observação apresentada e explicada em aula teórico-prática. De acordo com esta, nesse primeiro contato com o terreno, devem identificar e registar: equipamentos, cenários, trajetos, transportes, locais de sociabilidade, ruídos, cheiros, cores, grupos sociais, pessoas e personagens, que se destacaram no "olhar". (Guia Orientador da UC Antropologia e Sociologia, 2017, ESEL).

12 No segundo momento, após o reconhecimento do terreno e a seleção dos locais (realizado em sala de aula), "o olhar" deverá ser centrado sobre um dos lugares de interação com o objetivo de observar as dinâmicas das interações sociais quotidianas entre os atores que circulam no espaço em observação. (Guia Orientador da UC Antropologia e Sociologia, 2017, ESEL).

13 São oito turmas, numa média aproximada de 40-45 estudantes por turma teórico-prática.
} 


\subsection{Ensinar Quem?}

Ensinar quem? Nesse contexto, os não antropólogos podem ser abordados como nativos no bom sentido à Malinowski, para "compreender o olhar do nativo"- quem são os estudantes?

Na sua maioria são jovens de 18 anos no primeiro ano do ensino superior, que não tiveram ciências sociais nos seus currículos e sim ciências naturais ${ }^{14}$. Predomina entre esses alunos o modelo de conhecimento positivista, no qual a objetividade é o mote, tal como as dicotomias cartesianas corpo/mente e natureza/cultura, e para quem só existem universais no conhecimento (a definição). Por sua vez, há uma pequena minoria de estudantes trabalhadores em outras classes etárias, detentores do conhecimento sobre a realidade social e para quem o senso comum e o conhecimento científico não se distinguem. Há ainda outros grupos minoritários - estudantes dos PALOP, e, em anos anteriores, também alguns estudantes militares ${ }^{15}$. Nesse contexto, deparamo-nos com um grande desafio - o que faço e como faço para que a mensagem chegue a grupos tão heterogêneos, com experiências de vida e saberes tão diversos? ${ }^{16}$

O próprio espaço da sala de aula é então um espaço de diferença, a partir do qual se estimula o exercício de compreensão da diversidade, a partir da experiência dos estudantes, sobretudo nas aulas teórico-práticas (análise e discussão de textos). Para melhor adotar as estratégias de ensino e aprendizagem e saber se os estudantes tiveram um contato prévio com as disciplinas de sociologia e de antropologia, é realizado um teste de diagnóstico no primeiro dia de aula, antes da apresentação do programa da unidade curricular ${ }^{17}$. Esse teste é constituído por um conjunto de perguntas fechadas para a caracterização de algumas variáveis sociodemográficas (por exemplo, idade, gênero, naturalidade, residência, proveniência geográfica, estudante trabalhador/militar); e para conhecer se existe alguma familiaridade com antropólogos e sociólogos (conhece antropólogos/sociólogos; leu algum livro de antropologia/sociologia). Constam também desse questionário um conjunto de perguntas abertas, com o intuito de identificar o conhecimento prévio dos estudantes sobre essas áreas disciplinares e as suas expectativas relativas à unidade curricular (o que é a Antropologia? A Sociologia? Qual a expectativa? E o que gostaria de ver abordado nesta unidade curricular?).

Aquilo que temos verificado ao longo desses anos é que a maioria dos estudantes não conhece antropólogos, nem sociólogos, não leram nenhum livro de antropologia e/ ou sociologia e não tiveram a disciplina no seu percurso escolar. Para a questão sobre o que é a Antropologia, alguns estudantes respondem que não sabem, que nunca ouviram falar. Mas a maioria responde, sendo as respostas mais frequentes, estuda a evolução do Homem; estuda os comportamentos, e algumas respostas referem a sociologia estuda a sociedade e a antropologia estuda o indivíduo em sociedade.

\footnotetext{
${ }^{14}$ Ver perfil do estudante que acessa pela primeira vez na ESEL (2016/2017) em: www.esel.pt.

15 Os estudantes PALOPS são um contingente especial. Há também estudantes emigrantes que já fizeram o ensino secundário em Portugal. As principais nacionalidades nos últimos anos têm sido moldavos, ucranianos e brasileiros.

16 Questão semelhante colocou Tatiana Gerhardt (2019) na reflexão que faz da sua experiência docente de antropologia na graduação (bacharelado) em Saúde Coletiva. Aliás, em trabalhos futuros, seria muito pertinente estabelecer o diálogo com essas experiências em outras graduações de saúde, que não só a enfermagem.

17 Este questionário é anônimo.
} 
É a partir das respostas dos próprios estudantes que começamos a primeira aula sobre a história da antropologia, no seio das ciências sociais, e abordamos os conceitos de cultura e sociedade.

\subsection{E os Estudantes, que Expectativas têm em Relação a esta Unidade Curricular?}

Das respostas a essa questão, selecionamos algumas que ilustram certa regularidade nas expectativas dos estudantes nos últimos 10 anos $^{18}$ :

Nos dá a conhecer de que modo a enfermagem se adequa as diferentes religiöes. Os comportamentos humanos em função da comunidade onde estão inseridos. (Q11 - 18 anos)

Ganhar competências úteis na área social, enquanto desempenhar o papel de enfermeiro, como viver em contexto hospitalar. (Q1 - 19 anos)

Um enfermeiro precisa saber relacionar-se com os pacientes e familiares deste, pois tem como objectivo cuidar, tanto a nível físico como psicológico. (Q2 - 18 anos)

Compreender alguns comportamentos dos futuros clientes de forma a conseguir cuidar destes da melhor maneira. (Q3 - 19 anos)

Comportamento de um enfermeiro com os seus pacientes, ambiente hospitalar e comunidade. (Q4 - 17 anos)

Aprender a comunicar. (Q5 - 18 anos)

Ética, valores, modos de pensar e agir, a maneira de lidar com outros em casos de conflito. (Q6 - 18 anos)

Saber lidar com comportamentos e situações inesperadas de uma forma calma e lógica. Adquirir uma melhor experiencia na resolução de conflitos. Aprender a manipular as pessoas de uma forma saudável. (Q7 - 18 anos)

Enfermagem não contém apenas uma componente cientifica, mas também uma componente social, visto que vamos interagir com pessoas, logo é importante tentar entende-la. [...] temas relacionados com o cérebro humano e como funciona o cérebro de um doente psiquiátrico. (Q8 - 17 anos)

Ajude a compreender o outro. (Q9 - 18 anos)

Pelos exemplos apresentados, podemos reconhecer que alguns desses estudantes têm como expectativa que a unidade curricular seja um guia de autoajuda, onde eles vêm aprender sobre os comportamentos humanos, a gerir conflitos, como se comportar em contextos de saúde, designadamente nos hospitais. A ênfase na gestão do conflito é recente. Não tendo se aprofundado nessa questão e não sabendo muito bem como explicá-la, coloco como uma hipótese possível para esses estudantes, que não tiveram ainda contato com os serviços de saúde (alguns nunca entraram num hospital), a influência dos mass média e das redes sociais, que nos últimos anos circulam com notícias várias sobre tensões entre profissionais de saúde e utentes dos serviços de saúde ${ }^{19}$. Ou então, na mesma lógica de aprender a lidar com os comportamentos individuais, na linha da psicologia, disciplina que eles têm no ensino secundário.

\footnotetext{
18 Este questionário é anônimo.

19 Note-se que estas respostas foram obtidas antes da situação de pandemia de COVID-19.
} 
Tal como anteriormente referimos, é a partir das respostas dos estudantes às questões O que é a antropologia? O que é a sociologia? que começamos a primeira aula teórica sobre a história da antropologia no seio das ciências sociais, seguida de uma aula teóricaprática em que são analisados dois textos: um, sobre alguns excertos da Carta de Pêro Vaz de Caminha (MENDONÇA; VENTURA, [1999 ou 2000]) e o outro "Body ritual among the Nacirema" (MINNER, 1956), para refletir sobre a construção do "outro". Este é o primeiro texto discutido, sendo frequentemente as reações dos estudantes de horror, expressando a classificação dos comportamentos como que povo horrível, são muito violentos, é preciso pagar para serem tratados, que obsessão com o corpo; mas raramente são reconhecidos como práticas da própria sociedade. Apenas, habitualmente, um ou dois estudantes por turma reconhecem a própria sociedade; em algumas turmas, nenhum estudante a reconheceu. Nesses casos, só se dá o clic quando se pede para identificarem no mapa onde fica situado tal povo - os Nacirema. Quando o descobrem, é habitualmente a manifestação de espanto dos estudantes seguida de gargalhada geral, tendo havido já situações em que alguns estudantes verbalizam que engraçado vermo-nos ao contrário. Na mesma sessão letiva, relativamente à Carta de Pêro Vaz de Caminha (MENDONÇA; VENTURA, [1999 ou 2000]) exploramos a descrição que é feita do corpo e das "vestes" dos índios nesse documento, solicitando aos estudantes que imaginem uma situação inversa. Isto é, como seria a descrição dos índios sobre os "homens barbudos" saídos das naus, levantando aí já a noção de higiene (tão cara nas ciências da saúde) associada à civilização, com a questão: quem, nessa situação, usava o banho?

\subsection{Que Questões Enunciam esses Estudantes de Enfermagem?}

Após a seleção dos conteúdos programáticos e elaborada a ementa (o programa), quando os tentamos operacionalizar em sala de aula, somos confrontadas com as questões formuladas pelos estudantes: para que serve a antropologia num curso de enfermagem? Não entendo para que serve? É um saber abstrato? Qual é a definição de Antropologia? Qual a definição de Cultura? Para além de quererem a definição e manifestarem a sua frustração e perplexidade face à nossa resposta - Para quem? Depende das perspetivas teóricas e disciplinares, surge de imediato o questionamento sobre a noção de "universal". Os estudantes colocam também interrogações sobre a objetividade/subjetividade do conhecimento científico em ciências sociais, comparando-o com as ciências naturais, hierarquizando-o e discutindo a validade da metodologia nessas áreas disciplinares.

Que estratégias pedagógicas utilizar então para passar do saber abstrato ao concreto? Por um lado, optamos pelo uso dos documentários e, como anteriormente referimos, pela realização de um exercício de observação etnográfica (observar, ouvir, sentir, registar e classificar). Selecionamos um excerto de um dos trabalhos de grupo, que permite expressar como os estudantes integraram o conhecimento na experiência da observação da diversidade, aguçando sua sensibilidade para os detalhes da vida cotidiana e suas conexões:

[...] por existir uma "obrigação fundamental de uma descrição completa dos fenómenos, sem procurar o que é sensacional e singular e ainda amenos 
o que é risível ou bizarro [...]" (MALINOWSKI, 1997, p. 25), no primeiro momento focamo-nos em anotar tudo o que víamos e ouvíamos e não apenas o que nos parecia estranho ou diferente. Posteriormente, organizamos toda essa informação numa grelha de observação que dividimos em território e "ritmos do lugar".

Logo desde o início do exercício, destacou-se a meteorologia, dado no dia em questão ter chovido intensamente, o que acreditamos ter influenciado não só a vida social, isto é, os comportamentos e interações dos atores sociais, como também a nossa própria observação.

Notámos uma predominância de cores escuras por todo o território, o que, possivelmente, terá sido uma consequência da meteorologia. Tal contrastou com o cenário característico da chuva, onde existe uma pluralidade de formas e padrões provenientes dos guarda-chuvas, trazendo, assim, alguma vivacidade àquele dia cinzento.

[...]

Foram-nos percetíveis vários odores, nomeadamente o cheiro à cerveja e, ainda, o cheiro a bolos nos dois cafés. Relativamente aos ruídos, comuns a todos os lugares do território, foram o som das sirenes que se ouviam frequentemente.

\subsection{Como Ensinar? Estratégias de Ensino/Aprendizagem}

Tem sido de acordo com a experiência de docência e com as questões que os estudantes colocam sobre a dificuldade em compreender a natureza abstrata da disciplina, que vão sendo afinadas as estratégias de ensino/aprendizagem. Para além da seleção de conteúdos de acordo com a tipologia de sessão letiva, em que se privilegia a discussão de textos sobre conteúdos abordados nas aulas teóricas, são visionados documentários, de cariz etnográfico, seguidos de debate sobre eles ${ }^{20}$. Como o programa está organizado em quatro dimensões de análise, tenta-se o visionamento de um documentário em cada um desses pontos. Assim, os documentários selecionados, dois "distantes" e dois "próximos", têm sido: "Margaret Mead: de observadora a observada" (RTP2, BBC 1985); “The Boatman" (Gianfranco Rosi, 1993); “Os lisboetas" (F. Truffaut, 2004) e "Nós os chineses" (Carlos Fraga, 2013).

A experiência fez com que a utilização do documentário sobre a Margaret Mead, que era visionado inicialmente só na $4^{\mathrm{a}}$ sessão letiva, depois da exposição de conteúdos teóricos sobre autores e métodos na formação histórica da disciplina, tivesse passado a ser visionado logo na primeira sessão letiva, depois da apresentação da unidade curricular e da equipe pedagógica. Fez-se essa alteração porque constatamos que, a partir daqui, era mais fácil para os estudantes compreenderem a história da disciplina, o que fazem os antropólogos e em que consistem "o trabalho de campo" e a etnografia. Nas aulas subsequentes, pede-se aos alunos para relembrarem o que viram sobre alguns dos antropólogos de referência, aludidos no documentário para além de Margaret Mead (como são por exemplo Franz Boas, Ruth Benedict), quando se abordam os temas

\footnotetext{
20 No primeiro dia de aulas, é disponibilizado na plataforma on-line o Guia orientador da UC no qual se apresenta a forma como se desenvolve a disciplina (objetivos de aprendizagem, programa, metodologia, avaliação e bibliografia) . Inclui também um cronograma das sessões letivas, em que está indicado o dia, a tipologia de sessão letiva, o nome do professor, o sumário e a referência bibliográfica dos textos a ler em cada sessão letiva.
} 
Cultura: identidade(s) e diferenciações (perspetivas teóricas sobre o conceito de cultura) e Do etnocentrismo ao relativismo cultural.

Tentamos que os estudantes compreendam que aquilo que se pretende abordar, como o grande chapéu, é a saúde como um fenômeno complexo. Este não pode ser analisado no isolamento disciplinar dos cursos de saúde. Para a sua compreensão, são importantes diferentes abordagens teórico-metodológicas, de acordo com as respetivas filiações disciplinares.

Os estudantes, em geral, só conseguem compreender/reconhecer a importância da existência de uma unidade curricular de Antropologia e Sociologia no currículo escolar de enfermagem quando se inicia o bloco temático III, relativo aos processos de adoecer e tratamento, à saúde e à doença. Porém, também nesse ponto tudo é novidade, uma vez que esses estudantes estão no $1^{\circ}$ semestre do curso de licenciatura e apenas têm, como manifestam, "cadeiras teóricas" (Epistemologia e História de enfermagem; Aprender ao longo da Vida; Psicologia; Anatomia, e Microbiologia), quando a sua expectativa era a de aprender a "fazer". Frequentemente, só em anos mais avançados ( $3^{\circ}$ ou $4^{\circ}$ ano) e em contextos de prática clínica, alguns estudantes admitem e verbalizam a importância dessa unidade curricular na compreensão das situações de prestação de cuidados de enfermagem. O que vai ao encontro da análise de Moreira e Masini (apud SARTORI, 2010, p. 107), quando eles afirmam que "[...] para que ocorra uma aprendizagem significativa, a nova informação deverá ancorar-se em conceitos relevantes já existentes na estrutura cognitiva de quem aprende" 21 .

\section{Epílogo: a ponte entre margens e fronteiras}

Foi a experiência de ensino em sala de aula que me foi criando os desafios para pensar e tentar estabelecer pontes. Para tal, foi necessário refletir sobre as fronteiras que saindo da margem e usando uma metáfora, ao atravessar a ponte, os estudantes vão encontrar. O que pretendo dizer é que a antropologia é pensada e sentida pelos estudantes (e alguns colegas da enfermagem) como um saber marginal, que pode ou não interessar pontualmente como a curiosidade de conhecer o exótico. Existe curiosidade face ao outro, mas a diferença só é reconhecida naquilo que é muito diferente e não no que está mais próximo, tornando-se para isso necessário, talvez, "des-exotisar" a disciplina ou o olhar ${ }^{22}$. Assim, fica a dúvida perante a necessidade manifestada pelos estudantes de um saber instrumental se aquilo que é importante a esse nível de ensino e nessa fase da formação acadêmica é trabalhar-se mais a construção de um "olhar antropológico" do que a de um "saber antropológico".

Nesse sentido, será então necessário criar as condições para estimular a curiosidade de aprofundar e de explorar mais tarde o "saber antropológico". Alguns estudantes do $3^{\circ}$ e $4^{\circ}$ ano verbalizaram-me informalmente: professora, agora é que entendo a importância de termos feito aquele trabalho de observação no $1^{\circ}$ ano ou agora no estágio hospitalar é que compreendi

\footnotetext{
${ }^{21}$ Sobre esta problemática e maior desenvolvimento do tema do ensino para não antropólogos, ver Ary Sartori (2010) e Tatiana Gerhardt (2019).

22 Para aprofundar este diálogo, ver os textos de Mariza Peirano (2006) e de Peter Fry (2006).
} 
como é importante a antropologia, agora é que devíamos ter (a disciplina). Como afirma Eunice Durham (2006, p. 183):

Penso que a Antropologia tem um papel importante em diversos cursos e carreiras. É parte integrante da formação em Ciências Sociais, mas tem um papel importante e às vezes essencial em outras carreiras, tais como Serviço Social, Arquitetura, algumas áreas da Saúde, Educação Física, Jornalismo, Psicologia - papel esse que não é exatamente o de ensinar a fazer pesquisa em Antropologia. O papel da Antropologia nesses cursos é apresentar um outro modo de pensar os problemas que são próprios dessas carreiras, e oferecer informações sobre a diversidade cultural.

Aprendi com a experiência, e nas discussões partilhadas com os colegas da equipe pedagógica, e fui adaptando a forma de abordar os conteúdos programáticos e as estratégias de ensino-aprendizagem, de acordo com a forma como se ia processando o encontro professor-docente e com o próprio grupo que estava à minha frente, na mesma linha do encontro etnográfico - com o outro. O que tinha para a partida como objetivo - transmitir conteúdos programáticos de acordo com o currículo escolar - foi algumas vezes alterado, face àquilo que o terreno e os nativos queriam conhecer. E aí reside o grande desafio de tentar motivar aqueles que, à partida, não se interessam por esse objeto de estudo, essa disciplina. Esse é o ponto em que é necessário e é mais difícil estabelecer pontes entre as margens e as fronteiras disciplinares. A título de exemplo, no mesmo semestre, noutras unidades curriculares, se fala no "Homem" como uma categoria universal; aqui pretendemos problematizá-la e, para tal, falar em humanidade. Os próprios estudantes estabelecem uma hierarquia entre a importância das disciplinas, que se manifesta na seleção das unidades curriculares a que faltam para estudar anatomia ${ }^{23}$. É bom pensar que à entrada do anfiteatro estão colocados dois esqueletos. E que, nos trotes, os estudantes mais velhos recebem os neófitos nesse anfiteatro, em que colocam na mesa (onde habitualmente se sentam os professores) esqueletos vestidos. Note-se, não quero com esses exemplos dizer que os estudantes de enfermagem não precisem aprender anatomia, mas sim chamar a atenção para o enquadramento da unidade curricular Antropologia e Sociologia, que se expressa também espacialmente e na jocosidade das relações interpessoais.

É a partir dessa realidade que pensamos também as margens disciplinares e que tentamos construir pontes, para além do conhecimento instrumental da utilidade da disciplina, ${ }^{24}$ por meio de um olhar antropológico que não se limite à arena acadêmica e profissional. Mas, que este seja integrado na visão de mundo, e não mais um conhecimento fragmentado que apenas se aciona quando é útil. Logo, pretendemos não reforçar o que acontece frequentemente na própria enfermagem, que sistematicamente critica modelos biomédicos e afirma a sua fronteira disciplinar como modelos de cuidar holísticos, mas em que as estruturas curriculares e as abordagens são frequentemente a dos modelos biomédicos - a de fragmentação do corpo em quadradinhos. Como é óbvio, no ensino e na prática de enfermagem, tal como em outros grupos, não estamos perante um corpo profissional homogêneo, havendo quem contrarie esse olhar e modus fazendi.

\footnotetext{
${ }^{23}$ Para dialogar lógicas de hierarquias entre áreas cientificas no campo da saúde, particularmente no campo da saúde colectiva, consultar Russo e Carrara (2015).

${ }^{24}$ Para aprofundar a discussão com outro grupo/formação disciplinar (A Educação), consultar Gusmão (2006) e Caria (2017).
} 
E é aqui que o conhecimento antropológico permite o "entendimento do conhecimento do nativo" (GEERTZ, 1997), construindo pontes num vaivém epistemológico, de num primeiro momento aprender a fazer a rutura com o senso comum (SILVA, 1990), "estranhar" o "familiar" (VELHO, 1987). Para num segundo momento, por meio da leitura e da análise dos textos e do exercício de observação etnográfica, retomar o seu conhecimento de senso comum nas questões relativas à saúde, corpo, doença, processos de adoecimento, tratamento e cuidados no sentido da noção de "experiência próxima",

É mais ou menos, aquele que alguém - um paciente, um sujeito, em nosso caso um informante - usaria naturalmente e sem esforço para definir aquilo que os seus semelhantes vêem, sentem, pensam, imaginam etc e que ele próprio entenderia facilmente, se outros o utilizassem da mesma maneira. (GEERTZ, 1997, p. 87)

E essa noção é fundamental para os estudantes de enfermagem, tanto no "entendimento da natureza do conhecimento antropológico" na formação de visão do mundo como futuros profissionais de saúde, mediadores por excelência de dois tipos de saberes, o dos doentes e famílias e o dos médicos. Assim, seria possível contrariar a tendência para o uso instrumental do conhecimento antropológico, ancorado na "experiência distante", que "[...] é aquele que os especialistas de qualquer tipo - um analista, um pesquisador, um etnógrafo, ou até um padre ou um ideologista - utilizam para levar a cabo seus objetivos científicos, filosóficos ou práticos [...]" (GEERTZ, 1997, p. 87), lidando com a diferença e a diversidade cultural transformada em "experiência próxima" e depois em "experiência distante" num duplo movimento teórico: o da antropologia e o da enfermagem.

\section{Agradecimentos}

Agradeço à Carla Teixeira e à Monica Saavedra pela leitura do texto, pelos comentários, discussão e sugestões. À professora Jean Langdon, agradeço pelo diálogo estabelecido relativo ao ensino da Antropologia em cursos de saúde ao longo de, quase, 20 anos. À Lina Antunes, socióloga com quem partilho a lecionação das disciplinas de antropologia e sociologia há 20 anos e à equipe pedagógica constituída nos últimos 10 anos por Telmo Calamote (2009); José Mapril (2010); Bruno Coelho (2011); Sofia Marinho (2012-2013); Luiz Vasconcelos (2013-2019); Margarida Moz (2014-2019) e Jorge Varanda (2017-2018) e Mónica Saavedra (2019). A todos, agradeço pela colaboração e pela discussão conjunta sobre temas, seleção de autores, textos e documentários, bem como pela avaliação da unidade curricular. 


\section{Referências}

CARIA, Telmo. A constituição do saber profissional: uma contribuição interdisciplinar sobre a dualidade do uso social do conhecimento. Análise Social, [s.l.], v. 224, p. 498-532, 2017.

COEHEN, Anthony. Signifying Identities: Anthropological Perspectives on Boundaries and Contested Identities. London: Routledge,1999.

DURHAM, Eunice. Ensino de Antropologia. In: GROSSI, Miriam; TASSINARI, Antonella; RIAL, Carmen (org.). Ensino de Antropologia no Brasil: formação, práticas disciplinares e além-fronteiras. Florianópolis: Nova Letra, 2006. p. 207-208.

FRY, Peter. Formação ou Educação: os dilemas dos antropólogos perante a grade curricular. In: GROSSI, Miriam; TASSINARI, Antonella; RIAL, Carmen (org.). Ensino de Antropologia no Brasil: formação, práticas disciplinares e além-fronteiras. Florianópolis: Nova Letra, 2006. p. 59-75.

GEERTZ, Clifford. Do ponto de vista dos nativos: a natureza do entendimento antropológico. In: GEERTZ, Clifford. O saber local: Novos ensaios sobre antropologia interpretativista. Rio de Janeiro: Editora Vozes, 1997. p. 85-107.

GEERHARDT, Tatiana Engel. Cultura e cuidado: dilemas e desafios do ensino da antropologia na graduação em saúde colectiva. Saúde e Sociedade, [s.l.], v. 28, n. 2, p. 38-52, 2019.

GOFFMAN, Erving. Desempenhos. In: GOFFMAN, Erving. A Representação do Eu na Vida Quotidiana. Petrópolis: Vozes, 1985. p. 169-197.

GUSMÃO, Neuza. Antropologia e Educação. História e trajectos/Faculdade de Educação UNICAMP. In: GROSSI, Miriam; TASSINARI, Antonella; RIAL, Carmen (org.). Ensino de Antropologia no Brasil: formação, práticas disciplinares e além-fronteiras. Florianópolis: Nova Letra, 2006. p. 299-331.

LANGDON, Jean; WIIK, Flavio. Antropologia, Saúde e doença: uma introdução ao conceito de cultura aplicado às ciências da saúde. Rev. Latino-Americana de Enfermagem, [s.l.], v. 18, n. 3, p. 174-181, 2010.

MALINOWSKI, Bronislaw. Os Argonautas do Pacífico Ocidental. Lisboa: Etnologia, [s.l.], v. 6-8, p. 17-38, 1997.

MENDONÇA, Manuela; VENTURA, Margarida. A Carta de Pêro Vaz de Caminha. Lisboa: Mar de Letras Editora, [1999 ou 2000].

MINNER, Horace. Body ritual among the Nacirema. American Anthropologist, [s.l.], v. 58, p. 503-507, 1956.

OLIVEIRA, Roberto Cardoso. O trabalho do antropólogo: olhar, ouvir, escrever. In: OLIVEIRA, Roberto Cardoso. O Trabalho do Antropólogo. São Paulo: UNESP, 1998. p. 17-35.

PEIRANO, Mariza. Há dez anos. In: GROSSI, Miriam; TASSINARI, Antonella; RIAL, Carmen (org.). Ensino de Antropologia no Brasil: formação, práticas disciplinares e alémfronteiras. Florianópolis: Nova Letra, 2006. p. 77-103.

RUSSO, Jane; CARRARA, Sérgio. Sobre as Ciências Sociais na Saúde Colectiva - com especial referência à Antropologia. Physis, [s.l.], v. 25, n. 2, p. 467-483, 2015.

SARTORI, Ary. A experiência como mediadora no ensino da antropologia para quem não vai ser antropólogo. 2010. 400p. Tese (Doutorado em Antropologia Social) - Centro de Filosofia e Ciências Humanas, Universidade Federal de Santa Catarina, Florianópolis, 2010.

SILVA, Augusto Santos. A ruptura com o senso comum nas ciências sociais. In: SILVA, Augusto Santos et al. (org.). Metodologia das Ciências Sociais. Porto: Afrontamento, 1990. p. 30-53. 
VELHO, Gilberto. Observando o familiar. In: VELHO, Gilberto. Individualismo e Cultura: notas para uma Antropologia das Sociedades Contemporâneas. Rio de Janeiro: Zahar Editores, 1987. p. 123-132.

\section{Maria Manuel Quintela}

Professora Coordenadora de Ciências Sociais no Departamento de Enfermagem de Saúde Comunitária da Escola Superior de Enfermagem de Lisboa (Portugal). Leciona e coordena as unidades curriculares: Antropologia e Sociologia (graduação); Antropologia e Saúde Pública (Mestrado em Enfermagem Comunitária) e Socioantropologia das doenças crônicas (Mestrado em Enfermagem Médico-cirúrgica). Doutorada em Antropologia Social e Cultural pelo Instituto de Ciências Sociais da Universidade de Lisboa; mestre em Antropologia e graduação em Antropologia Social pelo ISCTE-IUL. Graduação em Enfermagem e especialização em Enfermagem de Saúde pública. É investigadora no Centro em Rede de Investigação em Antropologia (CRIA - polo ISCTE-UL), onde coordena desde 2014 a Linha Temática Antropologia da Saúde. Investigadora no Centro em Rede de Investigação em Antrpologia (ISCTE-IUL), Lisboa, Portugal.

Endereço profissional: Escola Superior de Enfermagem de Lisboa, Avenida Professor Egas Moniz, 1600096. Lisboa, Portugal.

E-mail: mariamanuel.quintela@gmail.com

ORCID: https://orcid.org/000-002-6815-9662

\section{Como referenciar este artigo:}

QUINTELA, Maria Manuel. Ensinar Antropologia para não Antropólogos: experiências e fronteiras em enfermagem. Ilha - Revista de Antropologia, Florianópolis, v. 24, n. 1, e80664, p. 52-67, janeiro de 2022. 